\title{
Cross-cultural validation of the Educational Needs Assessment Tool in RA in 7 European countries
}

\author{
Mwidimi Ndosi ${ }^{1 *}$, Alan Tennant ${ }^{2}$, Ulrika Bergsten ${ }^{3}$, Marja Leena Kukkurainen $^{4}$, Pedro Machado $^{5}$, \\ Jenny de la Torre-Aboki ${ }^{6}$, Thea PM Vliet Vlieland ${ }^{7}$, Heidi A Zangi ${ }^{8}$ and Jackie Hill'
}

\begin{abstract}
Background: The Educational Needs Assessment Tool (the ENAT) is a 39-item patient questionnaire originally developed in the UK to assess educational needs of patients with rheumatoid arthritis (RA). The objective of this study was to assess the cross-cultural validity of the ENAT in 7 European countries.

Methods: The ENAT was translated into Dutch, Finnish, Norwegian, Portuguese, Spanish and Swedish versions by using Beaton's cross-cultural adaptation process, and was completed by a convenience sample of patients with RA in each country. The generated country-specific data were assessed for construct validity and were then pooled and assessed for cross-cultural invariance using Rasch analysis.

Results: Individual country-specific analysis showed adequate fit to the Rasch model after adjustment for local dependency within domains. When data from the different countries were pooled, the 39 items deviated significantly from Rasch model's expectations $\left(X^{2}=977.055, \mathrm{DF}=351, \mathrm{p}=0.000, \mathrm{PSI}=0.976\right.$ ). Again, most items within domains were found to be locally dependent, significantly affecting the fit. Consequently each domain was treated as a unit (i.e. testlet) and the ENAT was re-analysed as a seven-testlet scale resulting into a good fit to the Rasch model $\left(X^{2}=71.909 ; D F=63 ; p=0.207, P S I=0.951\right)$. A test of strict unidimensionality confirmed that all domains contributed to measuring a single construct. Cross-cultural non-invariance was discounted by splitting domains for DIF maintaining an excellent fit to the Rasch model. This allowed calibration of the ENAT into an interval scale.
\end{abstract}

Conclusion: The ENAT is a simple tool, which is a valid measure of educational needs of people with RA. Adjustment for cross-cultural non-invariance is available if data from the 7 European countries are to be pooled or compared.

Keywords: Cross-cultural validation, Outcome research, Patient education, Rasch analysis, Rheumatoid arthritis

\section{Background}

Rheumatoid arthritis (RA) is a chronic inflammatory, systemic disease largely affecting the synovium, which can lead to joint damage and bone destruction. It can affect the heart, lungs and eyes and causes severe disability, psychological distress and increased mortality $[1,2]$. Drug management aims to relieve symptoms and to modify the disease process. Despite new biologic treatments which are more efficacious and specific than

\footnotetext{
* Correspondence: m.e.ndosi@leeds.ac.uk

${ }^{1}$ Academic \& Clinical Unit for Musculoskeletal Nursing (ACUMeN), Section of Musculoskeletal Disease, Leeds Institute of Molecular Medicine, University of Leeds, Leeds, UK

Full list of author information is available at the end of the article
}

other drug treatments [3,4], the patients' improvement in health status and quality of life may depend on their ability and willingness to adhere to all their therapies and undertake self-care activities. Patient education is the process by which patients are prepared for the latter important undertaking [5].

Patient education is recommended as an integral part of rheumatic diseases management [6,7] and ranges from supplying patient information leaflets to well-structured self-management programmes. However, systematic reviews have suggested that non-targeted education does not deliver long-term effects in RA patients [8,9]. Consequently recommendations have been made for patient education to be more patient-centred and tailored to 
address individuals' educational needs [10]. In order to plan effective patient-tailored education, clinicians need to assess patients' perceptions of their educational needs.

The Educational Needs Assessment Tool (the ENAT) is a patient-completed questionnaire designed to help patients with rheumatoid arthritis identify their educational needs. It was originally developed with patients and practitioners in the UK and it comprises 39 items grouped into 7 domains, namely: managing pain (6 items), movement (5 items), feelings (4 items), arthritis process (7 items), treatments (7 items), self-help measures (6 items) and support systems (4 items). The items are 5-category rating scales with descriptors: "not at all important", "a little important", "fairly important", "very important" and "extremely important". This gives a total score of educational needs ranging from 0-156. In the early development of the ENAT, two pilot studies were conducted among patients with various forms of arthritis [11]. The first one (with 20 patients) found the ENAT acceptable and easy to use and in the second (with 97 patients) the ENAT demonstrated a good testretest reliability [11]. The original (English) ENAT was later completed by a sample of 125 patients with RA in the UK and its 7 domains demonstrated a good fit to the Rasch model indicating a good construct validity and supporting the unidimensionality of the scale [12].

Since patient education is a globally accepted part of treatment in RA and given the increasing need to undertake multinational studies, tools such as the ENAT also need to demonstrate a cross-cultural invariance (i.e. work in a consistent manner across countries) [13-15]. Thus cross-cultural validation of the ENAT would enable comparison of educational needs and data pooling across Europe. The objective of this research was to assess the cross-cultural validity of the ENAT in RA in 7 European countries.

\section{Methods}

\section{Patients}

This multicentre quantitative survey involved patients from the Netherlands, Finland, Norway, Portugal, Spain, Sweden and the UK. Each country was asked to provide at least 125 patients in order to achieve the minimum sample size recommended for Rasch analysis [16]. Apart from the Netherlands and Sweden, which used random sampling, all centres utilised convenience sampling methods to recruit patients from their rheumatology clinics, wards, day hospitals and databases. The inclusion criteria were age 18 or above, a positive diagnosis of RA and willingness to complete the ENAT. The exclusion criteria were (a) having any other rheumatic disease such as systemic lupus erythematosus, systemic sclerosis, psoriatic arthritis, ankylosing spondylitis and osteoarthritis, (b) inability to read or write and (c) those unwilling to participate. Participation was voluntary and each centre obtained an ethical approval from their local ethics committees.

\section{Measure}

The original (English) ENAT was translated into the respective language versions by using the cross-cultural adaptation process recommended by Beaton et al [17]. The adaptation process involved 5 steps: 1) Initial translation - from the original (English) language to the target language 2) synthesis of the translations 3) back (blind) translation into the original (English) language 4) expert committee review which decides on equivalence between the source and target versions and 5) test of the pre-final version - testing the "adapted" version with 30 patients. This process was facilitated by an initial "set-up" meeting where the parameters for adaptation were considered and formalised. At this meeting, emphasis was placed upon the importance of the "conceptual" meaning of the statements in the ENAT.

The translated versions of the ENAT were given to patients in their respective countries to complete as postal surveys, or before their clinic consultations. The ENATs were anonymous but contained patients' demographical data such as gender, age, educational background and self-reported disease duration.

\section{Statistical analysis}

Rasch analysis was used to assess the construct validity and the cross-cultural invariance of the ENAT [18]. Rasch analysis has been used in rheumatology in the development of new scales $[19,20]$, to test the psychometric properties of existing scales [21,22] and for cross-cultural validation of patient outcome measures $[14,23,24]$. Since the Rasch model provides formal representation of fundamental measurement; fit to the model implies a criterion-related construct validity [25], objectivity [26], reliability [27] and statistical sufficiency [28]. Given fit to the Rasch model, ordinal data from an instrument can be converted into an interval scale, and parametric analytical methods can be used [29]. A more detailed description of the Rasch measurement model and its use in rheumatology is given elsewhere [30].

In the current study, data from individual countries were analysed separately and as pooled data, and subjected to Rasch analysis using RUMM2020 software [31]. Since the response format of the ENAT is polytomous, we utilised the Masters Partial Credit Model parameterisation [32]. Both the country-specific datasets and pooled data were assessed for fit, reliability and unidimensionality. The ideal fit values are given at the bottom of the Rasch analysis results table. In addition, the residual correlation matrix was examined and items that had a correlation of \pm 0.3 were considered to 
display a local dependency [33]. These locally dependent items were combined into a "testlet". A testlet is defined as a subset of items that is treated as a measurement unit in test construction, administration and/or scoring [34]. The data, in the form of testlets were then tested for fit, unidimensionality and invariance. Strict unidimensionality was assessed by analysis of the principal components of the standardised residuals, the loadings upon which give rise to two sets of items to generate independent estimates, which are then compared using the independent t-test method suggested by Smith [35]. The reliability of the ENAT was assessed by Person Separation Index (PSI) which provides the estimate of the internal consistency of the scale using the logit value for each person as opposed to the raw score used in Cronbach's alpha [36].

The test of invariance (DIF analysis) was based on person factors such as gender, age, disease duration, educational background and country. To allow for comparisons, the continuous data (age and disease duration) were converted into categorical variables by splitting them at their country-specific medians. Education was categorised as basic (up to secondary education) or higher (high school - university) education. Item characteristic curves for each testlet were checked for any significant DIF with respect to any person factor. Since there were 7 countries, post-hoc analysis of crosscultural DIF (Tukey test) was performed to ascertain cross-cultural DIF patterns. Subsequently the testlets affected with uniform DIF were "split" for DIF in order to adjust for the bias [37]. To avoid type I errors due to multiple testing, the $p$-values for fit statistics and DIF analyses were Bonferroni-adjusted to the alpha level (i.e. $\mathrm{p}=0.05 /$ number of tests carried out) [38].

\section{Results}

\section{Sample characteristics}

The sample of 1042 comprised 135 patients from Finland, 165 from the Netherlands, 137 from Norway, 123 from Portugal, 230 from Spain, 125 from Sweden and 125 from the UK. Their country-specific gender distribution, median age, median disease duration and educational background are summarised in Table 1.

\section{Individual country fit}

Initially the data from each country was fitted to the Rasch model separately (Table 2). Local dependency was observed within each domain, and so the 39 items were grouped into 7 domains (testlets) and re-analysed. Fit to the Rasch model was then satisfied in each country including unidimensionality, with the exception of Portugal, where marginal multi-dimensionality was observed. An analysis of differential item functioning showed absence of bias for age, gender, educational level and disease duration across all countries except Spain, where two items (movement and feelings) showed bias for gender and disease duration.

\section{Pooled data}

Initial Rasch analysis of the 39 items from the pooled data revealed significant deviations from the expectations of the Rasch model $\left(X^{2}=977.055, \mathrm{DF}=351\right.$, $\mathrm{p}=0.000)$ and a high reliability $(\mathrm{PSI}=0.976)($ Table 2$)$. Item fit residuals had a mean of $1.018(\mathrm{SD}=4.014)$ and person fit residuals had a mean of $0.552(\mathrm{SD}=2.554)$. Nine items displayed fit residuals values outside the \pm 2.5 expected range and a probability less than the Bonferroni adjusted $\alpha$-value of 0.0013 indicating significant deviation from the model.

The patterns of the items' thresholds were examined and 5/39 items displayed borderline disordering. These items were: 1) Using acupuncture, ultrasound or hydrotherapy (pain) 2) Devices which would help me do practical things (Movement) 3) Why I am feeling down or depressed (Feelings) 4) How arthritis might affect my children or relatives (Arthritis process) 5) Times when I should call the doctor or nurse (Self-help measures). Examination of the category probability curves for the above items indicated the need to amalgamate two categories "a little important" and "fairly important" for all the five items. A trial rescoring improved the threshold ordering but the overall fit worsened, therefore the category structures of these items were not re-scored.

\section{Local dependency and unidimensionality}

Examination of the person-item residual correlation matrix revealed that most domain-specific items were

Table 1 Sample characteristics by country

\begin{tabular}{|c|c|c|c|c|c|c|c|c|}
\hline & Finland & The Netherlands & Norway & Portugal & Spain & Sweden & UK & Total \\
\hline Sample size & 135 & 165 & 137 & 123 & 230 & 125 & 125 & 1042 \\
\hline Percentage of females (\%) & 82.2 & 88.5 & 73.7 & 71.5 & 75.2 & 76.0 & 79.2 & 78.0 \\
\hline Median age (years) & 54 & 67 & 57 & 52 & 58 & 61 & 58 & \\
\hline Median disease duration (years) & 10 & 12 & 7 & 11 & 10 & 15 & 13 & \\
\hline Basic education $(n)$ & 53 & 29 & 105 & 67 & 111 & 50 & 105 & 473 \\
\hline Higher education (n) & 81 & 134 & 32 & 47 & 104 & 73 & 17 & 488 \\
\hline
\end{tabular}


Table 2 Rasch analysis results

\begin{tabular}{|c|c|c|c|c|c|c|c|c|c|c|}
\hline & \multirow[b]{2}{*}{ Analysis } & \multicolumn{2}{|c|}{ Item Fit Residual } & \multicolumn{2}{|c|}{ Person Fit Residual } & \multicolumn{2}{|c|}{ Chi Square Interaction } & \multirow[t]{2}{*}{ PSI } & \multirow[b]{2}{*}{$\mathbf{N}$} & \multirow{2}{*}{$\begin{array}{l}\text { Independent } \\
\text { T-Tests }(\mathrm{Cl})\end{array}$} \\
\hline & & Mean & SD & Mean & SD & Value (DF) & $p$ & & & \\
\hline \multirow[t]{2}{*}{ UK } & Analysis1 (initial) & 0.34 & 1.686 & -0.269 & 2.008 & $442.439(351)$ & 0.000 & 0.972 & 119 & $0.218(0.179-0.258)$ \\
\hline & Analysis 2 (Subtest) & 0.541 & 0.699 & -0.308 & 1.168 & $7.116(7)$ & 0.417 & 0.947 & 119 & $0.068(0.028-0.107)$ \\
\hline \multirow[t]{2}{*}{ The Netherlands } & Analysis1 (initial) & 0.294 & 1.669 & -0.393 & 2.285 & $130.721(78)$ & 0.000 & 0.967 & 163 & $0.215(0.181-0.249)$ \\
\hline & Analysis 2 (Subtest) & 0.433 & 1.365 & -0.335 & 1.235 & $14.511(14)$ & 0.412 & 0.944 & 153 & $0.042(0.006-0.078)$ \\
\hline \multirow[t]{2}{*}{ Finland } & Analysis1 (initial) & 0.190 & 1.611 & -0.347 & 2.195 & $94.144(39)$ & 0.000 & 0.961 & 133 & $0.215(0.178-0.253)$ \\
\hline & Analysis 2 (Subtest) & 0.333 & 1.037 & -0.364 & 1.342 & $14.977(14)$ & 0.380 & 0.900 & 130 & $0.078(0.040-0.116)$ \\
\hline \multirow[t]{2}{*}{ Norway } & Analysis1 (initial) & 0.171 & 1.438 & -0.393 & 2.025 & 73.617 (39) & 0.001 & 0.965 & 133 & $0.235(0.198-0.272)$ \\
\hline & Analysis 2 (Subtest) & 0.542 & 0.873 & -0.357 & 1.150 & $6.053(7)$ & 0.534 & 0.919 & 131 & $0.056(0.018-0.094)$ \\
\hline \multirow[t]{2}{*}{ Portugal } & Analysis1 (initial) & 0.426 & 1.355 & -0.515 & 2.624 & $56.025(39)$ & 0.038 & 0.985 & 114 & $0.211(0.171-0.251)$ \\
\hline & Analysis 2 (Subtest) & 0.309 & 0.901 & -0.449 & 1.337 & $2.625(7)$ & 0.917 & 0.975 & 114 & $0.105(0.065-0.145)$ \\
\hline \multirow[t]{2}{*}{ Spain } & Analysis1 (initial) & 0.610 & 2.531 & -0.351 & 2.485 & $781.797(351)$ & 0.000 & 0.981 & 187 & $0.214(0.183-0.245)$ \\
\hline & Analysis 2 (Subtest) & 0.544 & 0.854 & -0.375 & 1.293 & $17.450(14)$ & 0.233 & 0.963 & 186 & $0.022(-0.010-0.053)$ \\
\hline \multirow[t]{2}{*}{ Sweden } & Analysis1 (initial) & 0.307 & 1.377 & -0.248 & 2.032 & $93.612(39)$ & 0.000 & 0.972 & 119 & $0.303(0.263-0.342)$ \\
\hline & Analysis 2 (Subtest) & 0.406 & 0.941 & -0.322 & 1.146 & $5.409(7)$ & 0.610 & 0.944 & 118 & $0.061(0.021-0.101)$ \\
\hline \multirow[t]{2}{*}{ Pooled } & Analysis1 (initial) & 1.018 & 4.014 & -0.552 & 2.554 & 977.055 (351) & 0.000 & 0.976 & 968 & $0.185(0.171-0.198)$ \\
\hline & Analysis 2 (Subtest) & 0.847 & 1.475 & -0.466 & 1.381 & $71.909(63)$ & 0.207 & 0.951 & 951 & $0.048(0.034-0.063)$ \\
\hline \multicolumn{2}{|c|}{ Expected values for a perfect model fit } & 0 & 1 & 0 & 1 & & $>0.05$ & $>0.85$ & & 0.05 (or Lower $\mathrm{Cl}<0.05$ ) \\
\hline
\end{tabular}

$\mathrm{SD}=$ Standard deviation, $\mathrm{DF}=$ Degrees of freedom, $\mathrm{P}=\mathrm{X}^{2}$ probability, (significant $\mathrm{P}=$ item misfit), $\mathrm{PSI}=\mathrm{Person}$

separation index, $\mathrm{Cl}=$ Confidence intervals

locally dependent and this was significantly affecting the fit to the model. All domain-specific items were then amalgamated into a testlet (each testlet corresponding to one ENAT domain) and the ENAT was then reanalysed as a seven-testlet scale which showed an acceptable fit to the Rasch model $\left(\mathrm{X}^{2}=71.909 ; \mathrm{DF}=63\right.$; $\mathrm{p}=0.207$ ) (Table 2 and Table 3 ). The strict unidimensionality test revealed the proportion of significant t-tests to be $0.048(95 \% \mathrm{CI}=0.034-0.063)$ confirming its unidimensionality. The reliability of the final ENAT was excellent $(\mathrm{PSI}=0.951)$. All analyses were thereafter based on the domain (testlet) scores. The person-item threshold distribution indicated that only a small

\section{Table 3 Item (testlet) fit}

\begin{tabular}{lrlllll}
\hline Item & Location & SE & $\begin{array}{l}\text { Fit } \\
\text { residual }\end{array}$ & DF & $\boldsymbol{X}^{\mathbf{2}}$ & $\boldsymbol{P}$ \\
\hline Pain & 0 & 0.010 & 0.176 & 743.47 & 3.748 & 0.927 \\
\hline Movement & 0.014 & 0.010 & -0.304 & 784.07 & 12.637 & 0.179 \\
\hline Feelings & 0.097 & 0.011 & 3.760 & 775.61 & 14.563 & 0.104 \\
\hline Arthritis process & -0.139 & 0.009 & -0.309 & 756.16 & 13.326 & 0.148 \\
\hline Treatments & -0.061 & 0.009 & 1.843 & 762.92 & 7.538 & 0.581 \\
\hline Self-help & -0.060 & 0.010 & 0.274 & 769.69 & 9.104 & 0.428 \\
measures & & & & & & \\
\hline Support systems & 0.149 & 0.012 & 0.490 & 773.07 & 10.992 & 0.276
\end{tabular}

$\mathrm{SE}=$ Standard error, $\mathrm{DF}=$ Degrees of freedom, $\mathrm{X}^{2}=$ Chi Square statistic, $\mathrm{P}=$ $\mathrm{X}^{2}$ probability (significant $\mathrm{P}=$ item misfit) proportion of the sample was above the range of the measurement indicating the ability of the ENAT to capture well the educational needs of patients (Figure 1).

\section{Differential item functioning}

Following fit to the Rasch model, DIF analysis on the pooled data revealed DIF by gender, age, disease duration, educational background and by country. However, apart from domain 3 (feelings) which displayed a non-uniform DIF by gender, all the DIF was uniform. Post-hoc analyses revealed that the cross-cultural DIF was the most significant contributing factor.

The Dutch data alone contributed to DIF by country on 4 testlets (pain, feelings, treatments and support). Splitting for DIF by country resolved all the crosscultural DIF and most other sources of DIF. Testlet 2 (movement) continued to display uniform DIF by gender and by disease duration, while testlet 6 (self-help measures) had borderline DIF by educational background.

\section{Calibration of the ENAT into an interval scale}

Following the adjustment for the cross-cultural DIF, the ENAT maintained a good fit to the Rasch model $\left(\mathrm{X}^{2}=\right.$ 138.311, $\mathrm{DF}=162, \mathrm{p}=0.214$ ) and an excellent reliability $($ PSI $=0.951)$. The ENAT domain raw scores were mapped against the corresponding Rasch transformed scores (in logits) and were linearly transformed to 


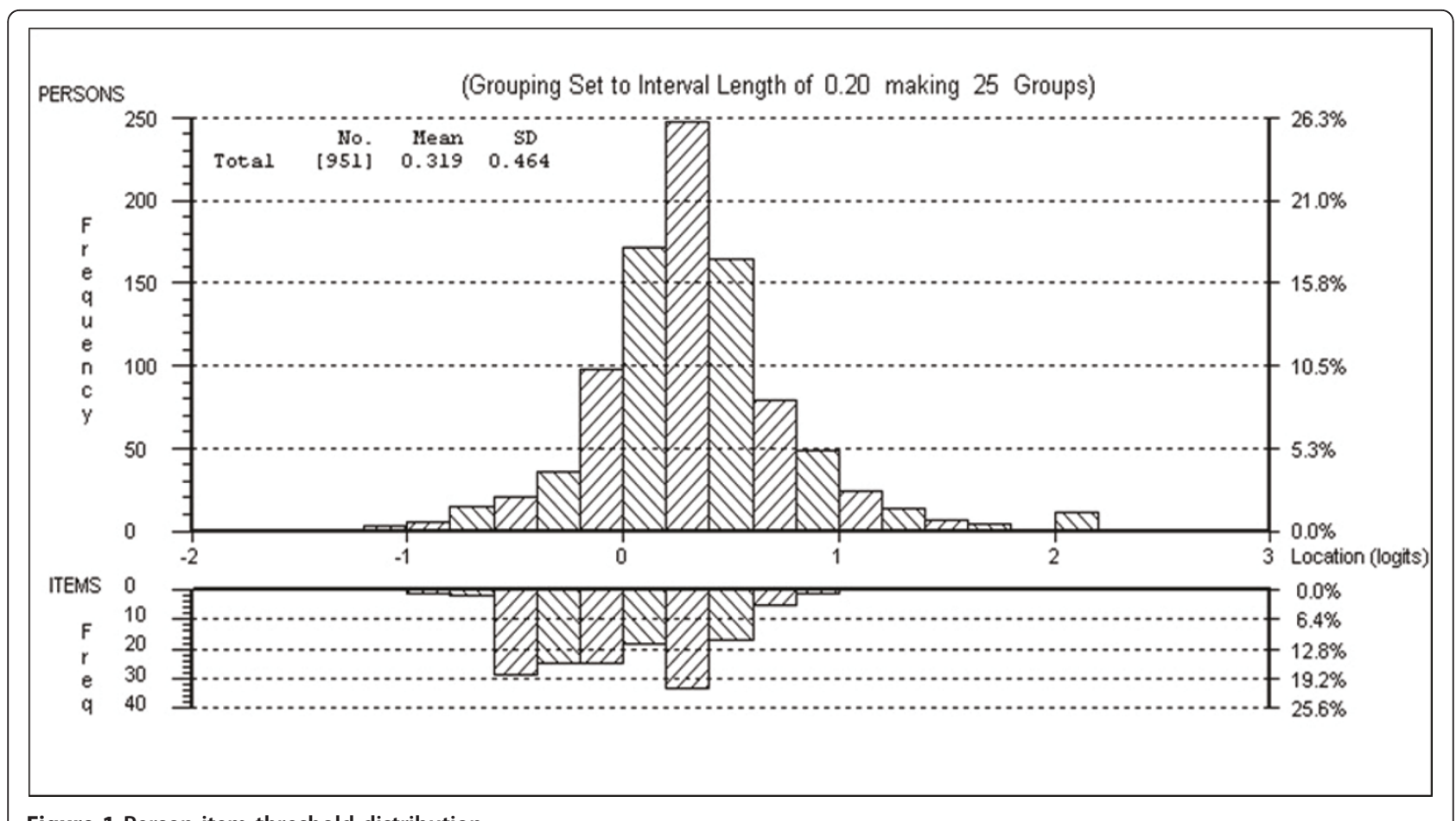

Figure 1 Person-item threshold distribution.

calibrate an interval-level scale of the same range (Table 4). A separate DIF-adjusted table was calibrated for the Dutch cohort (Table 5).

\section{Discussion}

This study has demonstrated that the ENAT satisfies Rasch model expectation in seven countries, with the possible exception of marginal multidimensionality in Portugal. The ENAT has been shown to be largely invariant by age, gender, educational level and disease duration with each country. When data were pooled, some DIF manifested, but was largely driven by country-specific DIF. When examined, most DIF was shown to cancel, but country DIF remained. Consequently when data are pooled across countries, adjustment must be made to accommodate the potential bias. Following such an adjustment, an interval scale transformation can be made, giving a raw-score interval metric table for general use.

A number of issues have arisen from this work. The breach of the local independence assumption has been shown to drive misfit to the Rasch model. This can be accommodated through the testlet design. This deals with the perennial problem of the tension between the clinimetric needs and the psychometric requirements of a measure when items that have clinical relevance are removed from the scale [39-41]. Leaving the items in the scale is advantageous in that the items may inform practitioners about educational needs at the finer level, while grouping them into testlets effectively accounts for the local dependence so satisfying the psychometric requirements [42].

The second issue is the implication of the lack of invariance across countries for pooling data in international studies. DIF analysis revealed that the cross-cultural DIF was responsible for most of the non-invariance in the data. Cross-cultural adjustment involved splitting the DIFaffected items by country, producing a scale with both etic (culturally-general) and emic (culturally-specific) items. This permits the scale to be culturally relevant while permitting comparisons across cultures and languages on the basis of the common etic items. Once the cross-cultural invariance was adjusted, the overall DIF improved including resolution of the non-uniform DIF by gender. When cross-cultural comparisons are to be performed, a separate DIF-adjusted conversion table for the emic data will need to be used. However, it should be stated that the magnitude of the observed DIF was only marginal, in that the maximum difference of location across countries within any educational need level (class interval) was only 0.18 logits. This suggests that the sample size of the pooled data was driving the statistical significance, and that the observed magnitude of DIF is below the level considered to be associated with measurement error [43].

As such, the ENAT can be used as a routine clinical checklist or as a research (or an audit) tool. In the 
Table 4 Conversion of raw ENAT domain scores to Rasch-transformed values.

\begin{tabular}{|c|c|c|c|c|c|c|c|}
\hline \multirow[t]{2}{*}{ Raw Score } & \multicolumn{7}{|c|}{ Rasch transformed score } \\
\hline & Pain & Movement & Feelings & Arthritis & Treatments & Self-help & Support \\
\hline 0.0 & 0.0 & 0.0 & 0.0 & 0.0 & 0.0 & 0.0 & 0.0 \\
\hline 1.0 & 2.7 & 1.9 & 1.8 & 2.1 & 2.2 & 1.5 & 1.8 \\
\hline 2.0 & 4.5 & 3.1 & 3.1 & 3.6 & 3.6 & 2.7 & 3.0 \\
\hline 3.0 & 5.6 & 4.1 & 4.0 & 4.6 & 4.6 & 3.6 & 4.0 \\
\hline 4.0 & 6.6 & 4.8 & 4.8 & 5.4 & 5.6 & 4.3 & 4.8 \\
\hline 5.0 & 7.3 & 5.6 & 5.7 & 6.2 & 6.3 & 5.0 & 5.5 \\
\hline 6.0 & 8.1 & 6.2 & 6.3 & 6.9 & 7.1 & 5.5 & 6.1 \\
\hline 7.0 & 8.7 & 6.8 & 7.0 & 7.5 & 7.8 & 6.1 & 6.8 \\
\hline 8.0 & 9.3 & 7.4 & 7.7 & 8.2 & 8.4 & 6.8 & 7.5 \\
\hline 9.0 & 9.9 & 8.1 & 8.3 & 8.9 & 9.1 & 7.5 & 8.1 \\
\hline 10.0 & 10.5 & 8.7 & 9.0 & 9.5 & 9.8 & 8.2 & 8.9 \\
\hline 11.0 & 11.1 & 9.3 & 9.7 & 10.3 & 10.4 & 9.1 & 9.6 \\
\hline 12.0 & 11.6 & 10.0 & 10.5 & 11.2 & 11.3 & 10.2 & 10.4 \\
\hline 13.0 & 12.2 & 10.7 & 11.4 & 12.0 & 12.1 & 11.3 & 11.3 \\
\hline 14.0 & 12.8 & 11.5 & 12.5 & 13.0 & 13.1 & 12.4 & 12.3 \\
\hline 15.0 & 13.4 & 12.3 & 13.9 & 13.9 & 14.1 & 13.5 & 13.9 \\
\hline 16.0 & 14.1 & 13.1 & 16.0 & 15.1 & 14.9 & 14.4 & 16.0 \\
\hline 17.0 & 14.6 & 14.3 & & 15.9 & 15.9 & 15.3 & \\
\hline 18.0 & 15.3 & 15.5 & & 16.9 & 16.7 & 16.2 & \\
\hline 19.0 & 16.1 & 17.4 & & 17.7 & 17.4 & 17.1 & \\
\hline 20.0 & 17.0 & 20.0 & & 18.4 & 18.2 & 18.0 & \\
\hline 21.0 & 17.9 & & & 19.2 & 19.0 & 18.9 & \\
\hline 22.0 & 19.3 & & & 20.0 & 19.7 & 20.0 & \\
\hline 23.0 & 21.1 & & & 20.8 & 20.5 & 21.7 & \\
\hline 24.0 & 24.0 & & & 21.6 & 21.3 & 24.0 & \\
\hline 25.0 & & & & 22.6 & 22.3 & & \\
\hline 26.0 & & & & 23.9 & 23.7 & & \\
\hline 27.0 & & & & 25.6 & 25.3 & & \\
\hline 28.0 & & & & 28.0 & 28.0 & & \\
\hline
\end{tabular}

former use, the clinician can use the ENAT as a simple checklist to assess perceived educational needs of patients before a clinic consultation. In this context, the perceived priority needs can be determined by looking at the completed ENAT without the need for scoring. In the latter use (measurement context) where the underlying latent construct of "educational need" is important, the Rasch-transformed scores give a common metric across all domains for comparative purposes. All domains contribute to measuring a single construct; thus adding up the domain scores is a sufficient statistic for estimating patients' educational needs (range $=0$ to 156$)$.

While the ENAT provides patients' perceived education needs, the health professional may know more about current treatment options and guidelines such as treat-to-target recommendations [44] which are beneficial to the patients. Having assessed patient's perceived educational priorities using the ENAT, the health professional can then discuss the needs arising with the patient, and provide more information about the available treatment goals and options in order to facilitate patient participation in their management. The main limitation of this study is that the ENAT is a self-completed questionnaire and consequently it did not reach the population of patients who cannot read and write. Further investigation of the marginal multidimensionality in Portugal would also be required. The ENAT can be obtained by contacting the corresponding author. 
Table 5 Conversion of raw ENAT domain scores to Rasch-transformed values for the Dutch dataset.

\begin{tabular}{|c|c|c|c|c|c|c|c|}
\hline \multirow[t]{2}{*}{ Raw Score } & \multicolumn{7}{|c|}{ Rasch transformed score } \\
\hline & Pain & Movement & Feeling & Arthritis & Treatments & Self-help & Support \\
\hline 0.0 & 0.0 & 0.0 & 0.0 & 0.0 & 0.0 & 0.0 & 0.0 \\
\hline 1.0 & 3.3 & 1.9 & 1.0 & 2.1 & 2.1 & 1.4 & 1.7 \\
\hline 2.0 & 5.5 & 3.2 & 1.9 & 3.6 & 3.7 & 2.6 & 2.9 \\
\hline 3.0 & 7.0 & 4.2 & 2.6 & 4.6 & 4.6 & 3.4 & 3.8 \\
\hline 4.0 & 8.2 & 4.9 & 3.2 & 5.4 & 5.5 & 4.2 & 4.5 \\
\hline 5.0 & 9.2 & 5.6 & 3.7 & 6.0 & 6.2 & 4.9 & 5.2 \\
\hline 6.0 & 10.1 & 6.3 & 4.3 & 6.8 & 6.9 & 5.5 & 5.9 \\
\hline 7.0 & 10.9 & 6.9 & 4.9 & 7.5 & 7.6 & 6.0 & 6.5 \\
\hline 8.0 & 11.7 & 7.4 & 5.4 & 8.1 & 8.3 & 6.6 & 7.3 \\
\hline 9.0 & 12.4 & 8.2 & 6.0 & 8.8 & 8.9 & 7.3 & 7.9 \\
\hline 10.0 & 12.9 & 8.8 & 6.7 & 9.4 & 9.6 & 8.0 & 8.7 \\
\hline 11.0 & 13.5 & 9.4 & 7.5 & 10.3 & 10.1 & 8.9 & 9.5 \\
\hline 12.0 & 14.0 & 10.1 & 8.5 & 11.1 & 10.8 & 10.0 & 10.3 \\
\hline 13.0 & 14.6 & 10.9 & 9.7 & 11.9 & 11.7 & 11.2 & 11.2 \\
\hline 14.0 & 15.0 & 11.6 & 11.1 & 12.9 & 12.4 & 12.4 & 12.4 \\
\hline 15.0 & 15.6 & 12.5 & 13.2 & 13.8 & 13.3 & 13.4 & 13.9 \\
\hline 16.0 & 16.1 & 13.3 & 16.0 & 15.0 & 14.2 & 14.3 & 16.0 \\
\hline 17.0 & 16.6 & 14.3 & & 15.8 & 15.1 & 15.3 & \\
\hline 18.0 & 17.1 & 15.7 & & 16.8 & 16.0 & 16.1 & \\
\hline 19.0 & 17.7 & 17.5 & & 17.6 & 16.7 & 17.0 & \\
\hline 20.0 & 18.4 & 20.0 & & 18.4 & 17.6 & 17.9 & \\
\hline 21.0 & 19.1 & & & 19.2 & 18.3 & 18.8 & \\
\hline 22.0 & 20.2 & & & 19.9 & 19.1 & 20.0 & \\
\hline 23.0 & 21.6 & & & 20.7 & 20.0 & 21.7 & \\
\hline 24.0 & 24.0 & & & 21.5 & 20.9 & 24.0 & \\
\hline 25.0 & & & & 22.6 & 22.0 & & \\
\hline 26.0 & & & & 23.8 & 23.4 & & \\
\hline 27.0 & & & & 25.6 & 25.4 & & \\
\hline 28.0 & & & & 28.0 & 28.0 & & \\
\hline
\end{tabular}

\section{Conclusion}

While Patient education is recommended as an integral part of rheumatic diseases management, [6,7] knowing what aspect of education may be required by a patient at any specific point of their treatment is an essential prerequisite to ensure that such needs are met. The ENAT offers a simple tool to help professionals judge what is required. It satisfied the strictest standards of measurement in all but Portugal, where marginal multidimensionality was observed, and can offer interval scaling when required. The scale can be used with confidence within the countries studied, but if data are to be pooled, then this will require adjustment within the framework of the Rasch measurement model, so providing the ability to compare educational needs across Europe.

\section{Acknowledgements}

This study was supported by a research grant from European League Against Rheumatism Standing Committee of Allied Health Professionals. Lillehammer Hospital for Rheumatic Diseases and Diakonhjemmet Hospital supported the study in Norway.

The authors wish to thank the following people:

1. Dr Arménio Cruz, Nursing School of Coimbra, Portugal and Dr. Armando Malcata, University Hospital of Coimbra, Portugal, for coordination and data collection.

2. Bente Hamnes, Lillehammer Hospital for Rheumatic Diseases, Lillehammer, Norway, for translation of the ENAT into Norwegian and data collection.

3. Amelia Carbonell-Jordá, Rheumatology Unit, San Juan University Hospital; Nieves Martínez-Alberola, Rheumatology Unit, Elda Hospital and Andrea García-Palao, Rheumatology Unit, Alicante General and University Hospital, Spain, for data collection.

4. Mike Horton, Psychometric Laboratory for Health Sciences, University of Leeds, UK, for advice on post-hoc DIF analyses.

\section{Author details}

${ }^{1}$ Academic \& Clinical Unit for Musculoskeletal Nursing (ACUMeN), Section of Musculoskeletal Disease, Leeds Institute of Molecular Medicine, University of 
Leeds, Leeds, UK. ²Department of Rehabilitation Medicine, Section of Musculoskeletal Disease, Leeds Institute of Molecular Medicine, Faculty of Medicine and Health, The University of Leeds, Leeds, UK. ${ }^{3}$ Research and Development Centre at Spenshult Hospital, Oskarström, Sweden. ${ }^{4}$ The Finnish Society of Rheumatology Nurses, Helsinki, Finland. ${ }^{5}$ Rheumatology Department, Coimbra University Hospital, Coimbra, Portugal. ${ }^{6}$ Rheumatology Department, Alicante General and University Hospital, Alicante, Spain. ${ }^{7}$ Department of Rheumatology and Department of Orthopaedics, Leiden University Medical Center, Leiden, The Netherlands. ${ }^{8}$ National Resource Center for Rehabilitation in Rheumatology (NRRK), Diakonhjemmet Hospital, Oslo, Norway.

\section{Authors' contributions}

$J H$ \& AT designed the study. JH, UB, JT, PM, MLK. TPMV \& HZ collected the data. MN \& AT undertook the statistical analysis. MN, AT \& JH interpreted the results. All authors participated in the preparation of the manuscript, read and approved the final version.

\section{Competing interests}

The authors declare that they have no competing interests.

Received: 22 November 2010 Accepted: 24 May 2011

Published: 24 May 2011

\section{References}

1. Scott D, Symmons D, Coulton B, Popert A: Long-term outcome of treating rheumatoid arthritis: results after 20 years. Lancent 1987, 1:1108-1111.

2. Pincus T, Callahan LF: Taking mortality in rheumatoid arthritis seriously predictive markers, socioeconomic status and comorbidity. J Rheumatol 1986, 13(5):841-845.

3. Singh JA, Christensen R, Wells GA, Suarez-Almazor ME, Buchbinder R, LopezOlivo MA, Ghogomu ET, Tugwell P: A network meta-analysis of randomized controlled trials of biologics for rheumatoid arthritis: a Cochrane overview. CMAJ 2009, 181(11):787-796.

4. Alonso-Ruiz A, Pijoan Jl, Ansuategui E, Urkaregi A, Calabozo M, Quintana A: Tumor necrosis factor alpha drugs in rheumatoid arthritis: systematic review and metaanalysis of efficacy and safety. BMC Musculoskeletal Disorders 2008, 9:52.

5. Hill J: Patient education in the rheumatic diseases. Nursing standard 1995, 9:25-28.

6. Combe B, Landewe R, Lukas C, Bolosiu HD, Breedveld F, Dougados M, Emery P, Ferraccioli G, Hazes JMW, Klareskog L, et al: EULAR recommendations for the management of early arthritis: report of a task force of the European Standing Committee for International Clinical Studies Including Therapeutics (ESCISIT). Annals of the Rheumatic Diseases 2007, 66(1):34-45.

7. Rheumatoid arthritis: The management of rheumatoid arthritis in adults. [http://www.nice.org.uk/nicemedia/pdf/CG79NICEGuideline.pdf]

8. Niedermann K, Fransen J, Knols R, Uebelhart D: Gap between short- and long-term effects of patient education in rheumatoid arthritis patients: A systematic review. Arthritis Rheum 2004, 51(3):388-398.

9. Reimsma R, Taal E, Kirwan J, Rasker J: Systematic review of rheumatoid arthritis patient education. Arthritis Rheum 2004, 51(6):1045-1059.

10. Koehn CL, Esdaile JM: Patient education and self-management of musculoskeletal diseases. Best Pract Res Clin Rheumatol 2008, 22(3):395-405.

11. Hardware B, Anne Lacey E, Shewan J: Towards the development of a tool to assess educational needs in patients with arthritis. Clinical Effectiveness in Nursing 2004, 8(2):111-117.

12. Hill J, Tennant A, Adebajo A: Further development of an educational needs tool (ENAT) for patients with rheumatoid arthritis. Arthritis and Rheumatism 2004, 50(9 suppl):616.

13. Petersen M, Groenvold M, Bjorner J, Aaronson N, Conroy T, Cull A, Fayers P, Hjermstad M, Sprangers M, Sullivan M: Use of differential item functioning analysis to assess the equivalence of translations of a questionnaire. Quality of Life Research 2003, 12(4):373-385.

14. Tennant A, Penta M, Tesio L, Grimby G, Thonnard J-L, Slade A, Lawton G, Simone A, Carter J, Lundgren-Nilsson Âs, et al: Assessing and Adjusting for Cross-Cultural Validity of Impairment and Activity Limitation Scales Through Differential Item Functioning Within the Framework of the Rasch Model: The PRO-ESOR Project. Medical care 2004, 42(1):I-37.
15. Scott N, Fayers P, Aaronson N, Bottomley A, de Graeff A, Groenvold M, Koller M, Petersen M, Sprangers M: The use of differential item functioning analyses to identify cultural differences in responses to the EORTC QLQ-C30. Quality of Life Research 2007, 16(1):115-129.

16. Linacre JM: Sample size and item calibration stability. Rasch Measurement Transactions 1994, 7:328-331.

17. Beaton DE, Bombardier C, Guillemin F, Ferraz MB: Guidelines for the process of cross-cultural adaptation of self-report measures. Spine 2000, 25(24):3186.

18. Rasch G: Probabilistic models for some intelligence and attainments tests Chicago: University of Chicago; 1960.

19. Keenan AM, Redmond AC, Horton M, Conaghan PG, Tennant A: The Foot Posture Index: Rasch analysis of a novel, foot-specific outcome measure. Archives of Physical Medicine and Rehabilitation 2007, 88(1):88-93.

20. Doward LC, MCKenna SP, Whalley D, Tennant A, Griffiths B, Emery P, Veale DJ: The development of the L-QoL: a quality-of-life instrument specific to systemic lupus erythematosus. British Medical Journal 2009, 68(2):196.

21. Peter MtK, Erik T, Mart AFJvdL: Rasch analysis of the Dutch health assessment questionnaire disability index and the health assessment questionnaire II in patients with rheumatoid arthritis. Arthritis Rheum 2008, 59(12):1721-1728.

22. Durez P, Fraselle V, Houssiau Fdr, Thonnard J-L, Nielens H, Penta M: Validation of the ABILHAND questionnaire as a measure of manual ability in patients with rheumatoid arthritis. Annals of the Rheumatic Diseases 2007, 66(8):1098-1105.

23. Gilworth G, Emery P, Gossec L, Vliet Vlieland TPM, Breedveld FC, Hueber AJ, Schett G, Tennant A: Adaptation and cross-cultural validation of the rheumatoid arthritis work instability scale (RA-WIS). Annals of the Rheumatic Diseases 2009, 68(11):1686-1690.

24. Tammaru M, McKenna SP, Meads DM, Maimets K, Hansen E: Adaptation of the rheumatoid arthritis quality of life scale for Estonia. Rheumatology International 2006, 26(7):655-662.

25. Rosenbaum PR: Criterion-related construct validity. Psychometrika 1989 54(4):625-633.

26. Rasch G: An informal report on a theory of objectivity in comparisons. Leyden: University of Leyden; 1967.

27. Bartholomew D: The Statistical Approach to Social Measurement. San Diego: Academic Press; 1996.

28. Anderen E: Sufficient statistics and latent trait models. Psychometrika 1977, 42:69-81.

29. Wright BD, Linacre JM: Observations are always ordinal; measurements, however, must be interval. Archives of Physical Medicine and Rehabilitation 1989, 70(12):857-860.

30. Tennant A, Conaghan P: The Rasch Measurement Model in Rheumatology: What is it and why use it? When should it be applied, and what should one look for in a Rasch paper. Arthritis and Rheumatism 2007, 57(8):1358-1362.

31. Andrich D, Lyne A, Sherdan B, Lou G: RUMM 2020. Perth: RUMM Laboratory; 2003.

32. Masters GA: Rasch model for partial credit scoring. Psychometrika 1982, 47:149-174.

33. Pallant JF, Tennant A: An introduction to the Rasch measurement model: An example using the Hospital Anxiety and Depression Scale (HADS). British Journal of Clinical Psychology 2007, 46:1-18.

34. Guemin L, Robert LB, David AF: Incorporating the Testlet Concept in Test Score Analyses. Educational Measurement: Issues and Practice 2000, 19(4):9-15.

35. Smith E: Detecting and evaluation the impact of multidimensionality using item fit statistics and principal component analysis of residuals. Journal of Applied Measurement 2002, 3:205-231.

36. Andrich D: Rasch models for measurement series: quantitative applications in the social sciences no. 68. London: Sage Publications; 1988.

37. Brodersen J, Meads D, Kreiner S, Thorsen H, Doward L, McKenna S: Methodological aspects of differential item functioning in the Rasch model. Journal of Medical Economics 2007, 10(3):309-324.

38. Bland J, Altman D: Multiple significance tests: the Bonferroni method. British Medical Journal 1995, 310(6973):170-170.

39. Velozo CA, Lai JS, Mallinson T, Hauselman E: Maintaining instrument quality while reducing items: application of Rasch analysis to a self- 
report of visual function. Journal of Outcome Measurement 2000,

4(3):667-680.

40. van der Velde G, Beaton D, Hogg-Johnston S, Hurwitz E, Tennant A: Rasch analysis provides new insights into the measurement properties of the neck disability index. Arthritis Rheum 2009, 61(4):544-551.

41. Keenan A, Mckenna S, Doward L, Conaghan P, Emery P, Tennant A:

Development and validation of a needs-based quality of life instrument for osteoarthritis. Arthritis Rheum 2008, 59(6):841-848.

42. Bradlow $E T$, Wainer $H$, Wang $X$ : A Bayesian random effects model for testlets. Psychometrika 1999, 64(2):153-168.

43. Wright B, Panchapakesan N: A procedure for sample-free item analysis. Educational and Psychological Measurement 1969, 29(1):23-48.

44. Smolen JS, Aletaha D, Bijlsma JWJ, Breedveld FC, Boumpas D, Burmester G, Combe B, Cutolo M, de Wit M, Dougados M, et al: Treating rheumatoid arthritis to target: recommendations of an international task force. Annals of the Rheumatic Diseases 2010, 69(4):631-637.

Pre-publication history

The pre-publication history for this paper can be accessed here: http://www.biomedcentral.com/1471-2474/12/110/prepub

doi:10.1186/1471-2474-12-110

Cite this article as: Ndosi et al:: Cross-cultural validation of the

Educational Needs Assessment Tool in RA in 7 European countries. BMC Musculoskeletal Disorders 2011 12:110.

\section{Submit your next manuscript to BioMed Central and take full advantage of:}

- Convenient online submission

- Thorough peer review

- No space constraints or color figure charges

- Immediate publication on acceptance

- Inclusion in PubMed, CAS, Scopus and Google Scholar

- Research which is freely available for redistribution

Submit your manuscript at www.biomedcentral.com/submit 